Abstract FRI0184 - Table

\begin{tabular}{|c|c|c|c|c|c|c|}
\hline & & Accepting $(\mathrm{n}=116)$ & Ambivalent $(n=182)$ & Indifferent $(\mathrm{n}=16)$ & Skeptical $(n=7)$ & $\mathrm{p}$ \\
\hline \multirow[t]{2}{*}{ Mean age (SD) } & & $55.5(12.6)$ & $54.2(12.5)$ & $58.8(13.2)$ & $53.6(10.2)$ & 0.459 \\
\hline & & $\%$ & $\%$ & $\%$ & $\%$ & \\
\hline \multirow[t]{2}{*}{ Sex } & Men & 19.0 & 23.1 & 43.8 & 43.9 & 0.090 \\
\hline & Women & 81.0 & 76.9 & 56.2 & 57.1 & \\
\hline \multirow{2}{*}{ RA duration } & $>$ median & 51.8 & 50.3 & 43.8 & 28.6 & 0.651 \\
\hline & $\leq$ median & 48.2 & 49.7 & 56.2 & 71.4 & \\
\hline \multicolumn{7}{|l|}{ Satisfaction } \\
\hline \multirow[t]{2}{*}{ Symptoms control } & Very/quite satisfied & 93.1 & 82.9 & 68.8 & 85.7 & 0.009 \\
\hline & Indifferent, quite/very unsatisfied & 6.9 & 17.1 & 31.2 & 14.3 & \\
\hline \multirow[t]{2}{*}{ Tolerance/side effects } & Very/quite satisfied & 79.7 & 57.0 & 50.0 & 57.1 & $<0.001$ \\
\hline & Indifferent, quite/very unsatisfied & 20.3 & 43.0 & 50.0 & 42.9 & \\
\hline \multicolumn{7}{|l|}{ Expectations } \\
\hline \multirow[t]{3}{*}{ Effect of the drug on symptoms } & Much/quite greater than expected & 69.6 & 53.3 & 75.0 & 57.1 & 0.031 \\
\hline & $+/$ As expected & 23.5 & 39.0 & 12.5 & 28.6 & \\
\hline & Quite/lower than expected & 7.0 & 7.7 & 12.5 & 14.3 & \\
\hline \multirow[t]{3}{*}{ Side effects/discomfort } & Much/quite greater than expected & 7.0 & 17.0 & 12.5 & 0.0 & 0.004 \\
\hline & +/- As expected & 27.0 & 39.6 & 25.0 & 57.1 & \\
\hline & Quite/lower than expected, or no side effects/discomfort & 66.0 & 43.4 & 62.5 & 42.9 & \\
\hline
\end{tabular}

Methods: ARCO was a study carried out on RA Spanish patients who initiated a SC biological drug 11-18 months prior to the study visit. Patients completed the Beliefs About Medication Questionnaire (BMQ). According to the scores obtained in the necessity $(\mathrm{N})$ and concerns $(\mathrm{C})$ sub-scales, patients were classified into 4 groups: accepting (high $\mathrm{N}[>3] /$ low $\mathrm{C}[\leq 3])$, ambivalent $(\mathrm{N}>3 / \mathrm{C}>3$ ), indifferent $(\mathrm{N} \leq 3 / \mathrm{C} \leq 3)$ and skeptical (low $N[\leq 3] /$ high $\mathrm{C}[>3]$ ). We studied demographic characteristics, expectations and satisfaction with the treatment by group.

Results: 321 patients ( $77 \%$ women) completed the $\mathrm{BMQ}, 92.8 \%$ scored $\mathrm{N}>3$ and $58.9 \% \mathrm{C}>3$. A higher $\%$ of men than women scored $\mathrm{N}<3(13.5 \%$ vs. $5.2 \%$, $\mathrm{p}=0.031$ ). The $\%$ who scored $\mathrm{C}>3$ was higher in those with low satisfaction with symptom control $(71.1 \%$ vs. $56.7 \%$ in satisfied/very satisfied, $p=0.098)$, or side effects $(72.1 \%$ vs. $52.0 \%, p<0.001)$, and in those with lower fulfillment of expectations of efficacy and tolerance $(p=0.006$ and $p<0.001)$. The combination of $\mathrm{N}$ and $\mathrm{C}$ scores identified 116 accepting (36.1\%), 182 ambivalent $(56.7 \%), 16$ indifferent $(5.0 \%)$ and 7 skeptical patients $(2.2 \%)$. There were no differences in age, gender, or RA duration among the groups, but differences were seen in the satisfaction with the treatment and in the fulfillment of the expectations (table). Ambivalent patients showed less satisfaction and lower fulfillment of expectations with the treatment received than accepting patients.

Conclusions: Patients with RA have strong beliefs about the need of their biological SC medication, but a high \% also expresses concerns. Beliefs, and especially concerns, seem to relate to the satisfaction and fulfillment of expectations of efficacy and tolerability or the drug, rather than to demographics or RA characteristics. Discussing expectations may be important when initiating a biological treatment.

Acknowledgements: Funded by MSD, Spain.

Disclosure of Interest: None declared

DOI: 10.1136/annrheumdis-2017-eular.3099

\section{FRI0185 A SYSTEMATIC REVIEW AND BIVARIATE META-ANALYSIS OF STUDIES THAT MEASURED ADALIMUMAB DRUG LEVELS BY ELISA TO DETECT TREATMENT RESPONSE IN RHEUMATOID ARTHRITIS}

S. Gavan ${ }^{1,2}$, K. Payne ${ }^{1}$, A. Barton ${ }^{2,3} .{ }^{1}$ Manchester Centre for Health Economics, The University of Manchester; ${ }^{2}$ National Institute for Health Research Manchester Musculoskeletal Biomedical Research Unit at Central Manchester University Hospitals NHS Foundation Trust; ${ }^{3}$ Centre for Musculoskeletal Research, The University of Manchester, Manchester, United Kingdom

Background: Previous research has demonstrated an association between circulating drug levels and treatment response in patients with rheumatoid arthritis that received the anti-TNF therapy adalimumab. Commercial ELISA assays are now available for use in routine practice to monitor anti-TNF drug levels at regular intervals. However, the ability to detect treatment response by measuring adalimumab drug levels using an ELISA is uncertain.

Objectives: The objectives of this research were to identify and synthesise all published studies that investigated the accuracy of measuring adalimumab drug levels by ELISA to detect treatment response in patients with rheumatoid arthritis. Methods: A systematic review identified all published studies that performed a receiver operating characteristic $(\mathrm{ROC})$ analysis to detect treatment response in patients with rheumatoid arthritis by measuring adalimumab drug levels using an ELISA. Medline and Embase were searched electronically from inception to August 2016. Two researchers independently identified studies for the review using a pre-defined inclusion criteria. Assay results were classified as positive if adalimumab drug levels exceeded the cut-point reported in each study. Study design characteristics, sample characteristics, and test outcomes from $2 \times 2$ tables (true-positive; false-positive; true-negative; false-negative) were extracted from each study. The quality of each study was assessed using the QUADAS-2. A hierarchical bivariate meta-analysis synthesised the findings of the ROC analyses to account for between-study heterogeneity and correlation between assay sensitivity and specificity.

Results: The search strategy identified 4,006 abstracts and four studies met the inclusion criteria of the systematic review. Patients received $40 \mathrm{mg}$ adalimumab every two weeks in all studies. Studies varied in their design and sample characteristics, but had low risk of bias and low concern of applicability to the research objective. The hierarchical bivariate meta-analysis estimated that measuring high adalimumab drug levels by ELISA detected treatment response with an average sensitivity of 0.95 ( $95 \% \mathrm{Cl}: 0.85-0.98)$ and specificity of 0.68 (95\% Cl: 0.28-0.92).

Conclusions: Measuring high adalimumab drug levels by ELISA in patients with rheumatoid arthritis appeared to be predictive of treatment response. However, the measurement of low adalimumab drug levels was less predictive of no response to treatment. In practice, test accuracy may be improved by measuring anti-drug antibodies alongside adalimumab drug levels. Given the imperfect accuracy of ELISA assays, the relative cost-effectiveness of drug level monitoring should be evaluated before being recommended for use in routine practice.

Acknowledgements: SG acknowledges support from a National Institute for Health Research Manchester Musculoskeletal Biomedical Research Unit Ph.D studentship. We also acknowledge support from MATURA, a stratified medicine initiative funded jointly by the Medical Research Council and Arthritis Research UK (MR/K015346/1).

Disclosure of Interest: None declared

DOI: 10.1136/annrheumdis-2017-eular.6242

\section{FRI0186 INFLUENCE OF IMMUNOGENICITY TO THE FIRST TNF-I THERAPY ON RESPONSE TO THE SECOND BIOLOGIC AGENT IN RA PATIENTS}

$\underline{\text { P. Bogas }}^{1}$, C. Plasencia ${ }^{1}$, D. Pascual-Salcedo ${ }^{2}$, G. Bonilla $^{1}$, E. Moral $^{1}$,

C. Tornero ${ }^{1}$, L. Nuño ${ }^{1}$, A. Villalba ${ }^{1}$, D. Peiteado ${ }^{1}$, A. Martinez ${ }^{2}$, B. Hernandez ${ }^{2}$, A. Balsa ${ }^{1}$. ${ }^{1}$ Rheumatology; ${ }^{2}$ Immunology, Hospital Universitario la Paz, Madrid, Spain

Background: There is currently no consensus on selecting a therapeutic target in patients (pts) non-responsive to their first TNF-inhibitors (TNF-i). The development of anti-drug antibodies (ADA) is a frequent cause of secondary inefficacy in our pts with TNF-i and there is evidence that those who develop ADA at their 1st TNF-i achieve a higher degree of response to the second one, compared to ADApts. Thus ADA measurement can help in choosing a therapeutic target in pts who failed to respond to their 1st TNF-i

Objectives: To assess if development of ADA to the 1st TNF-i determines better response when switching to a 2 nd TNF-i versus a nonTNF-i. As secondary objective, analyze whether the presence or absence of ADA to a 1st TNF-i influences the efficacy of a 2 nd TNF-i

Methods: Of a total of 144 pts that switched from infliximab or Adalimumab to a 2nd biologic agent (Etanercept, Rituximab, Tocilizumab, Adalimumab, Abatacept, Certolizumab and Infliximab), only 60 , who had measured drug levels (DL)/ADA at discontinuation of the 1st TNF-I, were included. Clinical response was evaluated with DAS28, Delta-DAS28 ( $\triangle \mathrm{DAS28})$ and EULAR response (E-resp) at 6 (v-6) and $12(v-12)$ months after initiating 2 nd biologic agent and at the last visit prior to drug discontinuation or ending of the study for those who did not interrupt the biological therapy (v-end). DL/ADA levels were measured by ELISA. Statistical analysis was performed using SPSS version 20.0

Results: Within the 60 pts who had measured DL/ADA at suspension of the 1st TNF-i, 26 (43\%) were ADA- (i.e. DL +). In this ADA- subpopulation, 50\% changed to a 2nd TNF-i; at $v-6$ there were no differences between switchers to a 2 nd TNF-i and switchers to a nonTNF-i in DAS28 (3.7 \pm 2.1 TNF-i vs 4.2 \pm 1.1 nonTNF-i, $\mathrm{p}=0.286), \Delta \mathrm{DAS} 28(1,4 \pm 2$ TNF-i, $1 \pm 1,2$ nonTNF-i, $\mathrm{p}=0,374)$ and resp-E $(75 \%$ good/moderate resp in TNF-I, $40 \%$ in nonTNF-i, $p=0,064)$. At $v-12$, switchers to a 2nd TNF-i showed a lower DAS28 $(2.5 \pm 0.6$ TNF-i, $3.9 \pm 0.9$ nonTNF-i, $p=0.009)$ and a higher good E-resp rate with a marginally significant difference $(80 \%$ in TNF-i, $22 \%$ in nonTNF-i, $p=0.071$ ). However, at v-end, pts with a 2nd nonTNF-i had better response (DAS28 $>5,1$ in $50 \%$ of TNF-i pts, $0 \%$ of nonTNF-i, $p=0.044$ ). Likewise $\triangle \mathrm{DAS} 28$ at $\mathrm{v}$-end was higher in the nonTNF-i group with trend to significance $(0,7 \pm 1,7$ TNF-i, $1,7 \pm 0,8$ nonTNF-i, $p=0,06)$. Along these lines, the 
good/moderate E-resp rate was higher in switchers to a nonTNF-i $70 \%$ in TNF-i, $8.3 \%$ in nonTNF-i, $\mathrm{p}=0.006)$. In ADA+ subpopulation $(\mathrm{n}=34)$, no differences were found in clinical response at $v$-end in DAS28 (3.7 \pm 1.2 TNF-i, $3.9 \pm 1.1$ non-TNF-i, $\mathrm{p}=0.64), \triangle \mathrm{DAS} 28(0,63 \pm 1,6$ in TNF-i, $1,4 \pm 1,4$ in nonTNF-i, $\mathrm{p}=0,35)$ and good/moderate E-resp rate ( $30 \%$ in TNF-i, $91 \%$ in nonTNF-i, $p=0,703)$. In pts who changed to a 2nd TNF-i, those with ADA to 1st TNF-i had a higher good response rate than ADA- pts $(65 \%$ in $A D A+, 30 \%$ in $A D A-, p=0.07)$

\begin{tabular}{|l|c|c|c|}
\hline $\begin{array}{c}\text { Demographic } \\
\text { characteristics }\end{array}$ & $\begin{array}{c}\text { ADA+ } \\
\text { subpopulation }\end{array}$ & $\begin{array}{c}\text { ADA- } \\
\text { Subpopulation }\end{array}$ & $p$ \\
\hline Age (years) & $62,3 \pm 14,6$ & $65,7 \pm 14,9$ & 0,203 \\
\hline Sex (female) & $28(82 \%)$ & $23(88 \%)$ & 0,719 \\
\hline Smokers & $7(20,6 \%)$ & $4(26 \%)$ & 0,537 \\
\hline BMI & $26,9 \pm 8,9$ & $23,9 \pm 4,2$ & 0,39 \\
\hline Disease duration (years) & $19,3 \pm 8,05$ & $24,1 \pm 8,2$ & 0,844 \\
\hline RF + & $32(94 \%)$ & $20(77 \%)$ & 0,067 \\
\hline Anti-CCP + & $32(94 \%)$ & $22(88 \%)$ & 0,641 \\
\hline Basal CPR & $15,1 \pm 18,2$ & $20,4 \pm 21,7$ & 0,46 \\
\hline Basal ESR & $41 \pm 27,9$ & $38 \pm 20$ & 0,28 \\
\hline Basal DAS & $5,31 \pm 1,4$ & $5,51 \pm 1,3$ & 0,18 \\
\hline
\end{tabular}

Conclusions: The development of ADA to the first TNF-i entails a better response when switching to a 2nd TNF-i, with a similar efficacy to the pts who switched to a nonTNF-i. In those pts who did not develop immunogenicity to the 1st TNF-I, there is a better response when changing therapeutic target. The ADA measurement can help to select the pts who can benefit from a 2nd TNF-i

Disclosure of Interest: None declared

DOI: 10.1136/annrheumdis-2017-eular.6688

\section{FRI0187 RADIOGRAPHIC PROGRESSION BY DISEASE ACTIVITY STATES IN PATIENTS WITH RHEUMATOID ARTHRITIS TREATED WITH SB2 OR REFERENCE INFLIXIMAB}

J.S. Smolen ${ }^{1}$, J.-Y. Choe ${ }^{2}$, E. Keystone ${ }^{3}$, Y.H. Rho ${ }^{4}$, Y. Lee ${ }^{4}$, S. Lee ${ }^{4} .{ }^{1}$ Medical University of Vienna, Vienna, Austria; ${ }^{2}$ Daegu Catholic University Medical Center, Daegu, Korea, Republic Of; ${ }^{3}$ Mount Sinai Hospital, University of Toronto, Toronto, Canada; ${ }^{4}$ Samsung Bioepis Co., Ltd., Incheon, Korea, Republic Of

Background: Based on the totality of evidence, SB2 has shown to be similar with reference infliximab (INF) and has been approved as a biosimilar by the European Medical Agency. It is, however, hitherto unknown, if SB2 also shares similar structural efficacy in the different disease activity states when compared with INF.

Objectives: To evaluate the disease activity by simplified disease activity index (SDAI) and clinical disease activity index (CDAl) at weeks 14, 30 and 54 in patients with rheumatoid arthritis (RA) treated with SB2 or INF from a phase III study and to assess the radiographic progression at week 54 in patients by disease activity states (remission, low disease activity [LDA], moderate disease activity [MDA], or high disease activity [HDA]).

Methods: Patients with RA were randomised to receive either SB2 or INF 3 $\mathrm{mg} / \mathrm{kg}$ at weeks $0,2,6$, and then every 8 weeks thereafter until week 46 with background methotrexate. Dose increments were allowed after week 30 by 1.5 $\mathrm{mg} / \mathrm{kg}$ up to a maximum dose of $7.5 \mathrm{mg} / \mathrm{kg}$. Disease activities by SDAI, and CDAl were compared at weeks 14,30 , and 54 . The radiographic progression was measured by modified Total Sharp Score (mTSS) at weeks 0 and 54 .

Results: Up to week 54, comparable proportions of patients achieved ACREULAR-index remission between SB2 and INF (by SDAl: 13/279 [4.7\%] vs. $13 / 283$ [4.6\%] at week $14 ; 24 / 250$ [9.6\%] vs. 29/263 [11.0\%] at week 30; 34/226 [15.0\%] vs. $24 / 224[10.7 \%]$ at week 54 ; by CDAl: $12 / 279$ [4.3\%] vs. $12 / 283$ [4.2\%] at week $14 ; 22 / 253[8.7 \%]$ vs. $31 / 265[11.7 \%]$ at week $30 ; 33 / 227[14.5 \%]$ vs. $24 / 225[10.7 \%]$ at week 54 in SB2 and INF, respectively). The proportions of radiographic non-progressors (defined as change in mTSS $\leq 0$ ) by disease activity were comparable between SB2 and INF at week 14, 30 and 54 (Table 1). Patients treated with SB2 as well as INF also exhibited the lowest progression of

\begin{tabular}{|c|c|c|c|c|c|c|c|c|c|}
\hline \multirow{3}{*}{\multicolumn{2}{|c|}{$\begin{array}{l}\text { Disease activiry state } \\
\text { at each visit }\end{array}$}} & \multicolumn{4}{|c|}{ CDAI } & \multicolumn{4}{|c|}{ SDAI } \\
\hline & & \multicolumn{2}{|l|}{ SB2 } & \multicolumn{2}{|l|}{$\mathrm{NNF}$} & \multicolumn{2}{|l|}{ SB2 } & \multicolumn{2}{|l|}{ NSF } \\
\hline & & \begin{tabular}{|c|} 
Radiographic \\
non-progressors
\end{tabular} & $\begin{array}{c}\text { Mean } \\
\text { change }\end{array}$ & \begin{tabular}{|c|} 
Radiographic \\
non-progressors
\end{tabular} & $\begin{array}{c}\text { Mean } \\
\text { change }\end{array}$ & $\begin{array}{c}\text { Radiographic } \\
\text { non-progressors }\end{array}$ & \begin{tabular}{|c|} 
Mean \\
change
\end{tabular} & \begin{tabular}{|c|} 
Radiographic \\
non-progressors
\end{tabular} & \begin{tabular}{|c|} 
Mean \\
change
\end{tabular} \\
\hline \multirow{4}{*}{ Week 14} & $\mathrm{HDA}$ & $43 / 62(69.4)$ & 0.44 & $4259(71.2)$ & 0.61 & $25 / 41(61.0)$ & 0.80 & $31 / 45(68.9)$ & 1.03 \\
\hline & IDA & $64 / 86(74.4)$ & 0.27 & $5782(69.5)$ & 0.64 & $81 / 105(77.1)$ & 0.10 & $63 / 89(70.8)$ & 0.45 \\
\hline & LDA & $43 / 56(76.8)$ & 0.54 & $49 / 58(84.5)$ & -0.38 & $44 / 58(75.9)$ & 0.63 & $53 / 64(82.8)$ & -0.27 \\
\hline & Remission & $7 / 9(77.8)$ & 0.17 & $68(75.0)$ & 1.44 & $799(77.8)$ & 0.17 & $79(77.8)$ & 1.00 \\
\hline \multirow{4}{*}{ Week 30} & $\mathrm{HDA}$ & $29 / 43(67.4)$ & 0.93 & $33 / 47(70.2)$ & 1.20 & $25 / 37(67.6)$ & 0.79 & $24 / 33(72.7)$ & 1.32 \\
\hline & IDA & $57 / 76(75.0)$ & 0.14 & $49,71(69,0)$ & 0.43 & $59 / .80(73.8)$ & 0.24 & $5884(69.0)$ & 0.54 \\
\hline & LDA & $55 / 4(74.3)$ & 0.40 & $5267(77.6)$ & -0.10 & $56 / 4(75.7)$ & 0.42 & $54.69(78.3)$ & .0 .23 \\
\hline & Remission & $1620(80.0)$ & 0.05 & $2224(91.7)$ & -0.13 & $17 / 21(81.0)$ & 0.07 & $20 / 22(90.9)$ & 0.07 \\
\hline \multirow{4}{*}{ Week 54} & HDA & $31 / 43(72.1)$ & 0.39 & $25 / 42(59.5)$ & 1.59 & $25 / 36(69,4)$ & 0.65 & $23 / 36(63.9)$ & 1.71 \\
\hline & IDA & $47 / 69(68.1)$ & 0.69 & $4666(69.7)$ & 0.30 & $50 / 73(68.5)$ & 0.57 & $44,68(64.7)$ & 0.35 \\
\hline & LDA & $51 / 67(76.1)$ & 0.20 & $6278(79.5)$ & 0.29 & $54 / 69(78.3)$ & 0.18 & $66.82(80.5)$ & 0.24 \\
\hline & Remission & $2833(84.8)$ & .0 .11 & $23 / 23(100.0)$ & -1.39 & $27 / 33(81.8)$ & .0 .08 & $23 / 23(100.0)$ & -1.22 \\
\hline
\end{tabular}

radiographic damage in remission and the largest progression in HDA, but also very small increases in mTSS in LDA and MDA, in line with previous findings on INF.

Conclusions: The proportion of patients achieving remission or LDA was comparable up to week 54 upon treatment with both SB2 and INF. Inhibition of radiographic progression was also comparable in each disease activity state. The proportion of radiographic non-progressors was also similarly high in patients achieving remission, and overall very low radiographic progression rates were seen even in LDA and MDA in both treatment arms. These data further confirm the comparability of SB2 and INF.

Disclosure of Interest: J. S. Smolen Consultant for: Abbvie, Amgen, AstraZeneca, Astro, Celgene, Glazo, Janssen, Lilly, Medimmune, MSD, NovartisSandoz, Pfizer, Roche, Samsung Bioepis, Sanofi, UCB, J.-Y. Choe Consultant for: Samsung Bioepis, E. Keystone Consultant for: Pfizer, Roche, Janssen, Amgen consultant/Pfizer, Roche, Janssen, Amgen, BMS, Merck. Merck, Celltrion, Samsung Bioepis, Y. H. Rho Employee of: Samsung Bioepis, Y. Lee Employee of: Samsung Bioepis, S. Lee Employee of: Samsung Bioepis DOI: 10.1136/annrheumdis-2017-eular.5524

\section{FRI0188 EFFECTIVENESS OF ADALIMUMAB COMBINATION THERAPY WITH METHOTREXATE AND NON-METHOTREXATE CSDMARDS: RESULTS FROM THE CORRONA RHEUMATOID ARTHRITIS REGISTRY}

D. Pappas ${ }^{1,2}$, J. Griffith ${ }^{3}$, C.A. Schlacher ${ }^{3}$, J.L. Suboticki ${ }^{3}$, R.W. Harrison ${ }^{2}$, Y. Shan ${ }^{2}$, C. Karki ${ }^{2}$, J.M. Kremer ${ }^{4} .{ }^{1}$ Columbia University, New York; ${ }^{2}$ Corrona, LLC, Southborough; ${ }^{3}$ AbbVie, Inc., Abbott Park; ${ }^{4}$ Albany School of Medicine, Albany, United States

Background: Combination therapy of methotrexate (MTX) with biologics results in superior outcomes vs. monotherapy. However, little is known on the effectiveness of adalimumab (ADA) combination therapy with non-MTX conventional synthetic disease modifying anti-rheumatic drugs (CSDMARD).

Objectives: To evaluate whether ADA in combination with non-MTX csDMARD has similar effectiveness as MTX combination therapy on clinical and patient report outcomes (PROs).

Methods: Adult RA patients, naïve to other monoclonal antibodies, who initiated standard dose ADA (40mg q2w) in combination with MTX or $>1$ non-MTX csDMARD between 2003-2016 and had a 6 month follow-up visit were included. The primary outcomes were mean change in clinical disease activity index (CDAl) and mean change in PROs ( $\mathrm{mHAQ}$, pain, fatigue, morning stiffness) from baseline to 6 months. Secondary outcomes included achievement of remission $(\mathrm{CDAl} \leq 2.8)$ /low disease activity (LDA: CDAl $\leq 10)$. Outcomes were evaluated adjusting for covariates that differed at the time of initiation using mixed model linear regression. Kaplan-Meier survival analysis was used to examine the persistency of ADA between the two groups.

Results: A total of 754 patients were included: $\mathrm{N}=519$ ADA+MTX and $\mathrm{N}=235$ ADA+non-MTX csDMARD. Patients on ADA+MTX were slightly younger (mean age: 54.5 vs 57.4 years), with shorter disease duration (median: 3 vs 5 years), more likely to be biologic naïve ( $77 \%$ vs $69 \%$ ) compared to patients on ADA+nonMTX csDMARD (all $p<0.05$ ). Disease activity and PROs were comparable in both groups at the time of initiation (mean CDAl: 20.4 vs 22.8 ; mean pain: 45.3 vs 45.9; mean fatigue: 46.3 vs 47.8 ; mean patient global assessment: 42.8 vs 42.9 (on a VAS $0-100$ ) in ADA+MTX and ADA+nonMTX csDMARD group respectively. Adjusted analysis showed that patients on ADA+MTX had significantly lower mean CDAl at 6 months and higher change in CDAl vs patients in the ADA+non-MTX csDMARD group $(p<0.05)$. In addition, patients on ADA+MTX were more likely to achieve LDA compared to the ADA+non-MTX csDMARD group (Table). Change in PROs and persistency of ADA was comparable in both groups.

Table: Outcomes at 6 months among $A D A+M T X$ and $A D A+$ nonMTX csDMARD therapy

\begin{tabular}{|c|c|c|c|c|}
\hline & ADA +MTX & $\begin{array}{c}\text { ADA + nonMTX } \\
\text { csDMARD }\end{array}$ & Unadjusted ${ }^{b}$ & Adjusted b,c \\
\hline $\begin{array}{c}6 \text { month } \\
\text { outcomes }\end{array}$ & Mean (SD) & Mean (SD) & $\beta(95 \% \mathrm{Cl})$ & $\beta(95 \% \mathrm{CI})$ \\
\hline $\begin{array}{l}\text { Mean CDAl at } 6 \\
\text { months }\end{array}$ & $11.9(11.5)$ & $15.7(13.1)$ & $4.07(2.09$ to 6.04$)$ & 3.15 (1.11 to 5.18$)$ \\
\hline Change in CDAI & $-8.8(13.4)$ & $-7.4(13.4)$ & $1.72(-0.85$ to 4.29$)$ & 3.15 (1.11 to 5.18$)$ \\
\hline Change in $\mathrm{mHAQ}$ & $-0.11(0.39)$ & $-0.1(0.4)$ & $0.01(-0.07$ to 0.08$)$ & $0.01(-0.07$ to 0.08$)$ \\
\hline Change in pain & $-10.1(26.5)$ & $-9.7(30.7)$ & $0.68(-4.51$ to 5.88$)$ & $1.61(-3.58$ to 6.80$)$ \\
\hline \multirow[t]{2}{*}{ Change in fatigue } & $-2.7(25.9)$ & $-5.3(25.1)$ & $-2.64(-9.13$ to 3.84$)$ & \begin{tabular}{|c|}
$-2.58(-9.22$ to 4.07$)$ \\
\end{tabular} \\
\hline & $\begin{array}{c}\text { Response rate } n \\
(\%)\end{array}$ & $\begin{array}{c}\begin{array}{c}\text { Response rate } \\
(\%)\end{array} \\
\end{array}$ & $\begin{array}{l}\text { Odds Ratio' }(95 \% \\
\text { CI) }\end{array}$ & $\begin{array}{l}\text { Odds Ratio** (95\% } \\
\text { CI) }\end{array}$ \\
\hline $\begin{array}{l}\text { Achievement of } \\
\text { Remission } \\
\text { (CDAls2.8) }\end{array}$ & $46(15.5 \%)$ & $13(8.6 \%)$ & $0.52(0.26,1.06)$ & $0.58(0.27,1.26)$ \\
\hline $\begin{array}{l}\text { Achievement of } \\
\text { LDA (CDAIS10) }\end{array}$ & $136(45.9 \%)$ & $47(31.1 \%)$ & $0.51(0.32,0.80)$ & $0.59(0.37,0.96)$ \\
\hline
\end{tabular}

mHAQ: modified Health Assessment Questionnaire; LDA: Low Disease Activity; nonMTX csDMARD: non-methotrexate conventional synthetic disease modifying anti-rheumatic drug. " Includes leflunomide, sulfasalazine, and hydroxychloroquine.
Compared with MTX combination therapy as a reference; 'Adjustedffor age, duration of RA, work status (part-time, full-time, disabled, retired, other), insurance status (none, private, Medicare), prior biologic count, MTX continuation, baseline CDAI, baseline patient pain.

Conclusions: In this real world study, patients on ADA+MTX had significantly greater improvements in disease activity compared to patients on ADA+nonMTX 